\title{
Assessing the Adaptation of a Thai Version of the Ryff Scales of Psychological Well-Being: A PLS-SEM Approach
}

\author{
Raul Calderon Jr. ${ }^{*}{ }^{\oplus}$, GunDo Kim², Chadchom Ratsameemonthon ${ }^{3}$, Suporntip Pupanead ${ }^{4}$ \\ ${ }^{1}$ Faculty of Sports Science, Kasetsart University, Kamphaeng Saen Campus, Kamphaeng Saen, Nakhon Pathom, Thailand \\ ${ }^{2}$ Department of Sports \& Leisure Studies, College of Healthcare \& Biotechnology, Semyung University, Jecheon, South Korea \\ ${ }^{3}$ Department of English, Didyasarin International College, Songkhla, Thailand \\ ${ }^{4}$ Faculty of Education and Development Science, Department of Physical Education and Sport, Kasetsart University, Kamphaeng \\ Saen Campus, Kamphaeng Saen, Nakhon Pathom, Thailand \\ Email: ^raulthedoc@yahoo.com, gdokim@gmail.com, leelie@hu.ac.th, feduspt@ku.ac.th
}

How to cite this paper: Calderon Jr., R., Kim, G., Ratsameemonthon, C., \& Pupanead, S. (2020). Assessing the Adaptation of a Thai Version of the Ryff Scales of Psychological Well-Being: A PLS-SEM Approach. Psychology, 11, 1037-1053. https://doi.org/10.4236/psych.2020.117068

Received: June 10, 2020

Accepted: July 24, 2020

Published: July 27, 2020

Copyright (c) 2020 by author(s) and Scientific Research Publishing Inc. This work is licensed under the Creative Commons Attribution International License (CC BY 4.0).

http://creativecommons.org/licenses/by/4.0/

Open Access

\begin{abstract}
Psychological well-being plays a significant role in the prevention of chronic diseases. Southeast Asian countries could prevent a rise in chronic diseases by having access to reliable and valid tools to study psychological well-being and its impact on disease prevention. The Ryff Scales of Psychological Well-being (RSPWB) is a leading instrument for measuring psychological well-being and has been used in research in many countries. However, in Thailand, little research exists on psychological well-being and its relation to health and disease because versions of the RSPWB have not been translated and validated for the Thai population. This study aimed to assess the adaptation of a 54-item Thai version of the RSPWB. A research questionnaire, which included the 54-item RSPWB was translated, piloted, and completed by 1122 Thai undergraduate students. Analyses included the use of partial least squares, structural equation modeling (PLS-SEM) - a second-generation statistical technique for testing complex path models. Results showed a PLS-SEM measurement model with 23-items demonstrating good convergent and discriminant validity and reliability. The PLS-SEM structural model showed significant positive path coefficients from six factors (autonomy, environmental mastery, purpose in life, personal growth, positive relations with others, and self-acceptance) to the second-order factor of psychological well-being. Moreover, the 23-item Thai version supported the same six-factor structure of the original RSPWB. In conclusion, the adapted 23-item Thai version is shorter in length, easy to administer, has robust psychometric properties, and helps to fill the current lack of reliable and valid psychological well-being instruments available in Thai. Lastly, this study provides a model for other Southeast Asian countries
\end{abstract}


to translate, pilot, and adapt the RSPWB into their local languages, which might help to facilitate further research in psychological well-being and its association with chronic diseases and health promotion.

\section{Keywords}

PLS-SEM, Ryff Scales of Psychological Well-Being, Thailand, Students, Validation

\section{Introduction}

Psychological well-being (PWB) plays a significant role in the prevention of chronic diseases. Hernandez et al. (2018) reported that PWB was related to a lowered incidence of health problems (including arthritis, cancer, diabetes, heart problems, hypertension, lung diseases, stroke, and venous thromboembolism) and slow progression of cardiovascular diseases and decreased mortality. Studies looking at the association between PWB and biological outcomes have reported that people with high levels of eudaimonic well-being (aka PWB) had lower levels of cardiovascular risks, daily salivary cortisol, longer duration of REM sleep, and pro-inflammatory cytokines (Ryff, 2013; Ryff et al., 2004).

PWB research has flourished in recent years (Ryff, 2013; Seligman, 2012) and has shown that improved PWB reflects a lower occurrence of mental problems and increased positive psychology, including hedonic well-being (such as happiness, life satisfaction, and positive affect) (Diener, 1984) and eudaimonic wellbeing (autonomy, environmental mastery, purpose in life, personal growth, positive relations, and self-acceptance) (Ryan \& Deci, 2001). However, the majority of this research has primarily benefited western countries (Deci \& Ryan, 2006) because most PWB instruments were developed in English. Thus, non-English speaking countries, like those in Southeast Asia, which experience high levels of chronic diseases (Dans et al., 2011; Dhillon et al., 2012), generally do not have access to validated PWB instruments in their local languages. To increase the amount of PWB research in Southeast Asian countries more sound screening tools to assess PWB are needed.

\subsection{The Ryff Scales of Psychological Well-Being (RSPWB)}

Early well-being research focused mostly on hedonic well-being, also referred to as subjective well-being. Early leaders in this area included work by Diener (1984) into the nature of subjective well-being and life satisfaction, Lyubomirsky \& Tucker (1998) into subjective happiness, and Deci \& Ryan (1990) into personality integration, to mention only a few. These researchers and others helped advance the understanding of the field of subjective well-being. However, one main criticism of subjective well-being research was that it lacked grounding in theory and had a limited construct focus. 
Subsequently, the work by Ryff (1989) addressed these criticisms by synthesizing the work of leading theorists such as Bühler's (1935) basic life tendencies that work toward the fulfillment of life, Allport's (1961) conception of maturity, Neugarten's (1968) descriptions of personality change in adulthood and old age, Jahoda's (1979) positive criteria of mental health, Erikson's (1994) psychosocial stage model, Jung's (1935) formulation of individuation, Rogers's (1961) view of the fully-functioning person, and Maslow's (1962) conception of self-actualization, and proposed a theory-based multidimensional model of PWB, sometimes referred to as eudaimonic well-being.

The PWB model, proposed by Ryff (1989), was developed to capture the concept of PWB by incorporating six dimensions (factors). The theoretical dimensions are 1) autonomy, 2) environmental mastery, 3) purpose in life, 4) personal growth, 5) positive relations with others, and 6) self-acceptance. These six dimensions taken together are thought to compose the theoretical construct of PWB. In other words, PWB is a composite construct consisting of multiple sub-constructs (factors). Each sub-construct (factor) contributes a unique and important aspect to the broader construct of PWB.

To measure these constructs, Ryff developed three versions of the RSPWB, including 84-, 54-, and 18-item versions. All three versions have been used, validated, and sometimes modified to five to seven items per construct in previous studies. The RSPWB has been used in over 350 studies and translated into numerous languages (Cheng \& Chan, 2005; Freire et al., 2016; Kitamura et al., 2004; Lapa, 2015; Ryff, 2013; Woo Kyeong, 2013). However, the majority of research using the RSPWB are mostly from English speaking and western countries. Therefore, a significant amount of the current knowledge and understanding of PWB primarily describes the United States and European populations and it remains unclear if the findings apply to Southeast Asian populations. To address these unanswered questions the RSPWB should be used to advance the understanding of PWB in Southeast Asian populations.

\subsection{Use of the RSPWB in Southeast Asian Countries}

A review of the literature reveals a huge gap in available instruments to measure PWB and its association with chronic diseases and health promotion in Southeast Asian countries. The first countries in Asia to modify the RSPWB for research purposes were China (Gao \& McLellan, 2018), Korea (Kim \& Lim, 2012), and Japan (Kitamura et al., 2004). More recently, Vietnam, Thailand, and Singapore, which are part of the 11 designated countries of Southeast Asia (Indonesia, Malaysia, Singapore, Philippines, East Timor, Brunei, Cambodia, Laos, Myanmar (Burma), Thailand, and Vietnam) have published works using the RSPWB. For example, Dang (2017) published the first study to evaluate the RSPWB in a Vietnamese population. This study indicated that the 84-item version of the RSPWB (14-items/construct) had good reliability. However, the study did not adequately describe the translation method used or reported psychometrics of the convergent and discriminant validity. In 2019, a study by Cal- 
deron Jr. et al. (2019) indicated good convergent and discriminate validity and reliability for an adapted 28-item Vietnamese version of the RSPWB. Also, the adapted 28-item Vietnamese version supported the original six-factor structure of the RSPWB.

Furthermore, a study by Klainin-Yobas et al. (2020) validated an 18-item version of the RSPWB for Thai and Singaporean samples, which included young adults aged $10-24$. This study showed adequate validity and reliability for the 18-item version for Thai and Singaporean young adults. However, the 18-item version only identified a two-factor structure. Thus, these findings showed that the 18-item version of the RSPWB did not support the 6-factor structure proposed by the original English RSPWB. The 18-item version of the RSPWB is the shortest of three RSPWB versions and has limited psychometric properties compared to the longer versions of 54 and 84 items. This might be one reason why only a two-factor structure was found. Unfortunately, the Klainin-Yobas et al. (2020) study did not evaluate the 54- or 84-item versions of the RSPWB in her study.

It should be noted that the original RSPWB has been in use for over 3 decades, yet only a handful of studies using the RSPWB, as described above, have been published on Asian populations and mostly in the last decade. Moreover, concerns about methods and appropriate statistical techniques used to adapt and modify the RSPWB have been raised. Inconsistencies have included using shorter versions of the RSPWB without explaining how the scale items were selected, changing the response item format from a 6-point Likert scale to a 2-point scale without stating a clear rationale, and using limited statistical techniques. To improve upon these inconsistencies it is recommended to use a statistical technique able to handle complex path models, maintain the original format of the RSPWB, and use a version of the RSPWB that has robust psychometric properties.

\subsection{The Current Study}

Thus, the overall aim of this study was to produce a reliable and valid Thai version of the RSPWB to help fill the existing gap in the PWB literature concerning Southeast Asian populations. The 54-item version of the RSPWB, which has robust psychometric properties, was selected and a standardized statistical procedure, using partial least squares structural equation modeling (PLS-SEM) was applied.

The specific aims to accomplish the above included:

1) Test the convergent and discriminant validity and reliability, using PLS-SEM, of a 54-item Thai version of the RSPWB.

2) Test the significance of the path coefficients of the six dimensions/factors (autonomy, environmental mastery, purpose in life, personal growth, positive relations with others, and self-acceptance) leading to the second-order construct of PWB.

3) Compare the factorial structure of the validated Thai version to the original 
English version of the RSPWB.

\section{Methods}

\subsection{Research Design}

This study used a cross-sectional design, a translated version of the 54-item RSPWB, and students from northern and central Thailand.

\subsection{Translation of the Questionnaire}

Professional translators translated the English questionnaire into Thai. A back translation (Thai to English) confirmed sufficient accuracy and consistency of the Thai questionnaire.

\subsection{Components of the Research Questionnaire}

The research questionnaire included a Thai 54-item version of the RSPWB and demographic questions. The original RSPWB was developed to measure the multidimensional nature of psychological well-being (Ryff, 1989). There are three versions of the RSPWB, with 84, 54, and 18 items, with 14, 9, and 3 items per construct, respectively. For this study, the 54 -item version was selected to minimize the overall length of the questionnaire and lessen survey fatigue. The six sub-scales (9-items per scale) of the 54-item version included 1) Autonomy (self-determination and independence), 2) Environmental Mastery (a sense of mastery and competence in managing one's environment), 3) Personal Growth (a feeling of continued development), 4) Purpose in Life (having goals in life and a sense of direction), 5) Positive Relations with Others (having warm, satisfying, trusting relationships with others), and 6) Self-acceptance (possessing a positive attitude towards the self). The six sub-scales are hypothesized to form the theoretical construct of PWB and changes in the six sub-scales will cause changes in the construct of PWB. Each sub-scale consists of a mix of positive and negative sentences. Participants responded using a six-point Likert scale ranging from 1 (strongly disagree) to 6 (strongly agree). Responses to negatively scored items (-) are reversed in the final scoring procedures so that high scores indicate high self-ratings on the sub-scale assessed. Reliability (internal consistency coefficients) for the different sub-scales in the original English RSPWB version range from 0.86 to 0.93 and show good validity (van Dierendonck, 2004). Dang (2017) and Calderon Jr. et al. (2019) reported internal consistency coefficients ranging from 0.69 to 0.92 in the 54 and 84-item Vietnamese versions of the RSPWB.

\subsection{The Pilot of the Questionnaire}

A group of Thai students $(\mathrm{N}=30)$ were selected to pilot the questionnaire. Alpha coefficients for the six subscales of the RSPWB ranged from 0.380 (SelfAcceptance-sub-scale) to 0.744 (positive relations-sub-scale). Test-retest coefficients ranged from 0.403 (Self-Acceptance-sub-scale) to 0.829 (environmental mastery-sub-scale). 


\subsection{Participants}

This study included 1122 full-time undergraduate students (male $=532$, female = 590) enrolled in two large public universities, one from the north and one from the central part of Thailand; both universities were ranked among the top 25 in the country.

At the northern university, approximately 1550 undergraduate students, representing different majors, were enrolled in 66 core courses (i.e., required courses all undergraduate students must complete before graduation) during the fall semester of 2016. Twelve courses (class clusters) were randomly selected from the list of the 66 core courses, this randomized cluster sampling method provided a representative sample of students. A total of 472 undergraduate students agreed to participate and completed the questionnaire.

At the central university, approximately 675 undergraduate students, representing different majors, were enrolled in 3 required health education classes, which students from all majors must take as a graduation requirement, during the fall semester of 2017. All three classes were selected. All students in these classes were eligible and invited to participate in the study, thus providing a representative sample of students. A total of 650 undergraduate students agreed to participate and completed the questionnaire.

Overall, students in this study represented 31 different majors, ages 17 - 26 (Mean $=19.9 / \mathrm{SD}=1.4)$, and class levels $(1 \mathrm{st}, 2 \mathrm{nd}, 3 \mathrm{rd}$, and 4th year).

\subsection{Data Collection}

A translated Thai questionnaire was used to collect the data (a copy is available upon request from the author). During the school years 2016-2017, researchers met students in the selected classes, with the permission of the instructors, and described the study aims and invited the students to participate in the study. Students completed either a paper questionnaire or an online version of the questionnaire.

Over $90 \%$ of selected students from the northern university filled out a paper questionnaire. Paper questionnaires were favored at this university by the research team because it was felt that it would achieve higher quality data. In one class there was not enough time to administer the paper questionnaire so students were given a link to the online questionnaire and asked to fill it out at their leisure.

Students from the central university were given the option in class to fill out the questionnaire using either the paper or online version. Approximately $60 \%$ of students opted to fill out the paper questionnaire the rest of the students accessed the online version of the questionnaire on their mobile phones. Most students completed the paper or online questionnaire between 15 - 25 minutes.

\subsection{Statistical Analyses}

Descriptive statistics in the pilot and main study were produced using SPSS/PC version 22. RSPWB missing data were imputed with the SPSS median imputa- 
tion method.

\subsubsection{A Partial Least Squares-Structural Equation Modeling (PLS-SEM) Approach}

PLS-SEM is a second-generation statistical technique for testing complex path models. PLS-SEM is an alternative to another commonly used statistical approach-covariance-based structural equation modeling (CB-SEM). In this study, the PLS-SEM statistical technique was chosen for three main reasons 1) PLS-SEM can provide unique theoretical insights and prevent the misspecification of statistical models and hence erroneous results; 2) PLS-SEM is the preferable statistical technique when a model includes both reflective and formative constructs; and 3) PLS-SEM should be used when a model includes formative factors and has more than 40 - 50 indicators (Lowry \& Gaskin, 2014).

A four-step approach for PLS-SEM analysis, proposed by Lowry and Gaskin (2014), and implemented in this study, is described below.

Step 1: model specification. Figure 1 shows the specified model that was tested. The figure shows the measurement model, which included six reflective first-order latent variables (LVs): 1) autonomy, 2) environmental mastery, 3) purpose in life, 4) personal growth, 5) positive relations with others, and 6) self-acceptance and the structural model, which included one second-order formative LV, PWB. Each first-order LV had nine indicators, which were hypothesized to reflect the theoretical construct of their corresponding LV. The direction of the indicator arrows is important as it determines whether the LV should be specified as a reflective or formative construct. Reflective construct arrows point from the construct (causal) to their indicators (effect). In other words, a change in the construct will cause a change in the indicators. On the other hand, formative construct arrows point in the opposite direction, from the indicators (causal) to their corresponding LV (effect). So, a change in the indicators will cause a change in the LV. PWB is a second-order formative construct because the arrows of the six LVs all point to it. Specifying reflective and formative LVs, as mentioned above, was important to prevent the misspecification of the statistical model and hence avoid erroneous results.

Step 2: determine the construct validity of reflective constructs. The SmartPLS2 software (Ringle et al., 2005) was used to establish convergent and discriminant validity using the factor analysis scheme of the PLS algorithm. An example of using SmartPLS2 to perform a factor analysis can be seen on Gaskination's YouTube channel (Gaskin, 2012) and a detailed description of how to assess the validity of multiple first-order reflective LVs is provided by Calderon Jr. et al. (2019).

Step 3: establish the reliability of the reflective constructs: Reliability is a measure of internal consistency required in reflective (internally correlated) LVs. To establish reliability, composite reliability measures should be greater than 0.700 (Chin, 1998). The PLS algorithm computes a composite reliability score for each LV. When using PLS-SEM, composite reliability is generally regarded as a more appropriate criterion to establish reliability vs. using Cronbach's Alpha 
(Hair et al., 2012).

Step 4: provide and interpret final statistics: In the last step, a summary of the path coefficients and significance levels of the structural model (Table 1) were calculated. The significant LVs/sub-constructs of the structural model were compared to the six LVs/sub-constructs of the original RSPWB.

This four-step approach provided a way to assess and establish the reliability and validity of the PWB measurement and structural models shown in Figure 1.

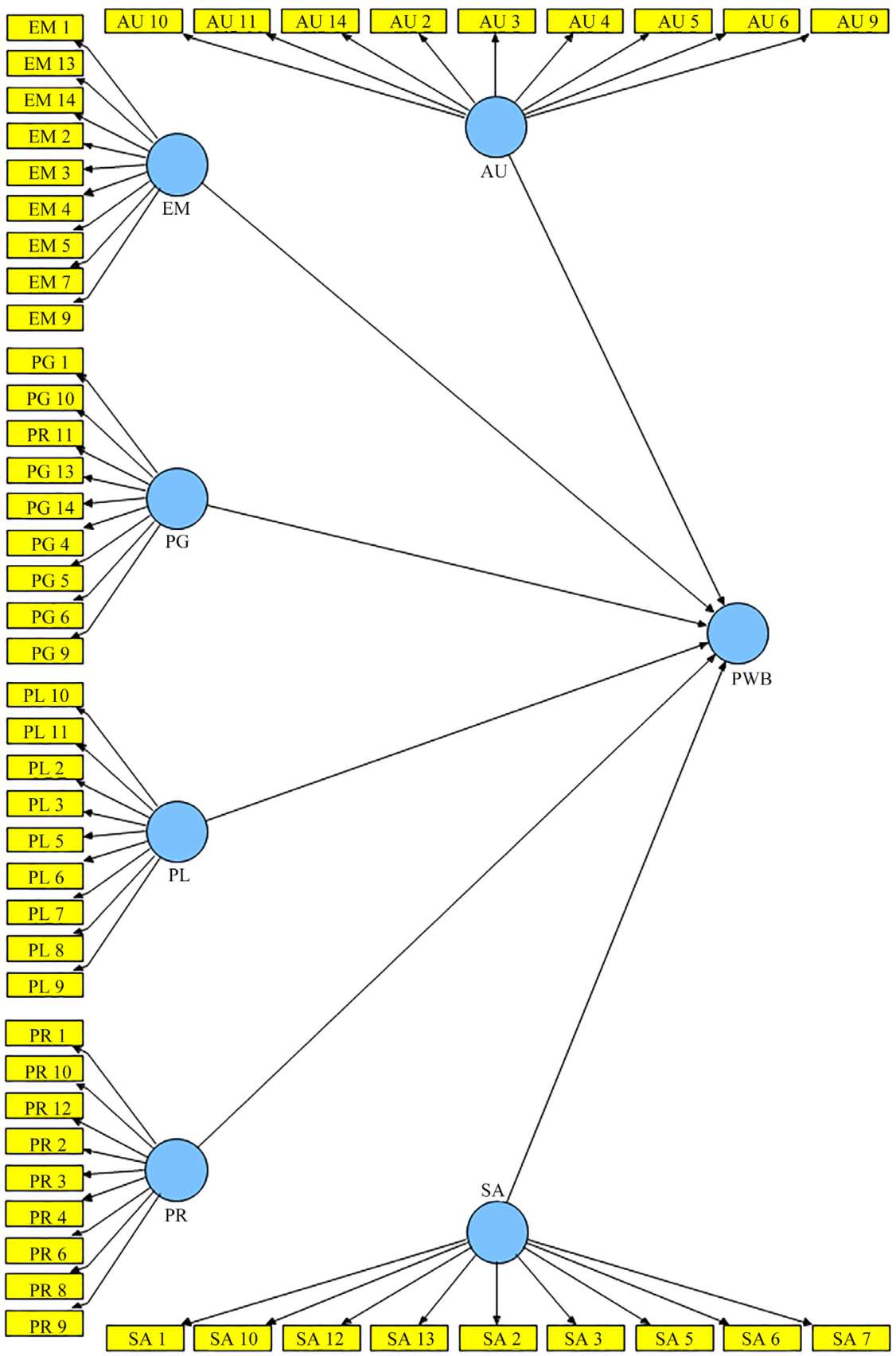

Figure 1. A Measurement Model with 54 indicators and the Structural model with six sub-constructs (Autonomy, Environmental Mastery, Personal Growth, Purpose in Life, Positive Relations with Others, and Self-Acceptance) of Psychological well-being. 
Table 1. Summary of the measurement and structural model psychometric properties of the Thai Version of the Ryff scales of psychological well-being.

\begin{tabular}{|c|c|c|c|c|c|c|c|}
\hline $\begin{array}{l}\text { Six Dimensions of } \\
\text { Psychological } \\
\text { Well-Being }\end{array}$ & Autonomy & $\begin{array}{l}\text { Environmental } \\
\text { Mastery }\end{array}$ & $\begin{array}{l}\text { Personal } \\
\text { Growth }\end{array}$ & $\begin{array}{l}\text { Purpose in } \\
\text { Life }\end{array}$ & $\begin{array}{l}\text { Positive } \\
\text { Relations }\end{array}$ & $\begin{array}{l}\text { Self- } \\
\text { Acceptance }\end{array}$ & $\begin{array}{l}\text { Thai Version of } \\
\text { Psychological } \\
\text { Well-Being }\end{array}$ \\
\hline
\end{tabular}

1. Validation of the Measurement Model

\subsection{Convergent Validity}

1.1.1. Items in model with significant T-Statistic greater than 1.96 .

Au2, Au4, Au6, Au10, (Loading coefficients are Au11, Au14 not listed in this table)

\subsection{Discriminant Validity}

$\begin{array}{ll}\begin{array}{ll}\text { 1.2.1. Items in final } \\ \text { model with loading }\end{array} & \mathrm{Au} 2(0.6321) \\ \text { coefficients }>0.45 & \mathrm{Au} 10.9731) \\ & \mathrm{Au} 11(0.8512) \\ \end{array}$

Em2 (0.9995) $\quad \operatorname{Pg} 1(0.7298)$

Em4 (0.5143) $\quad$ Pg4 (0.7775) Pl5 (0.8481)

Em7 (0.6732) Pg6 (0.7533) Pl8 (0.7582)

Em9 (0.4678) Pg10 (0.7884) Pl10 (0.9922)

Em13 (0.9472) Pg13 (0.9905)

1.2.2. Average loading coefficient per

0.76

dimension

1.2.3. Square Root of the

Average Variance $\quad 0.777$

Extracted (AVE)

1.3. Composite Reliability 0.8543

\section{Validation of the Structural Model}

$\begin{array}{ll} & \mathrm{Au}->\mathrm{PWB} \\ \text { 2.1. Standardized Path } & 0.2514 \\ \text { Coefficients } & \end{array}$

Em -> PWB

Pg $->$ PWB

Pl -> PWB

0.2938

0.3074

0.2296

Coefficients

0.2514

\subsection{T-Statistics}

(significant if $>1.96$ )
15.0343
17.4009

17.7737
Pr $->$ PWB

0.142

Sa $->$ PWB

Pr1, Pr2,

Pr3, Pr4,

Pr6, Pr8,

Pr9, Pr10,

$\operatorname{Pr} 12$

$\mathrm{Sa} 1, \mathrm{Sa}$,

$\mathrm{Sa} 3, \mathrm{Sa} 5$,

Sa6, Sa7,

Sa10

Sa1 (0.5811)

Pr4 (0.7603) Sa2 (0.6386)

Pr12 (0. 9320) Sa3 (0.6649)

Sa10 (0.9540)

These 47 indicators, of the original 54 indicators, significantly converged onto their respective

dimensions.

These 23 items, of the 47 items from above, demonstrated significant discriminant validity.

Average loadings of $>0.7$ supports discriminant validity of dimensions.

These coefficients were larger than the AVE coefficients of each comparative dimension, thus providing additional support of discriminant validity.

The composite reliability of each dimension exceeded the recommended minimum value of 0.7 , thus showing significant reliability of the items of each dimension.

All path coefficients were highly statistically significant, thus supporting the relationship between each hypothesized dimension and PWB (see Figure 1). 


\subsubsection{Sample Size and Power}

The sample size when using PLS-SEM is commonly determined by either multiplying 10 times the scale with the largest number of formative indicators or by multiplying 10 times the largest number of structural paths directed at a particular construct in the structural model (Lowry \& Gaskin, 2014). This study had six structural paths (see Figure 1) directed at one second-order construct, which means the study needed a minimum sample size of $60(10 \times 6)$. The $1122 \mathrm{stu}-$ dents in this study far exceeded the minimum sample size for power.

\subsection{Ethical Consideration}

The IRB of the university approved this study. Students received written informed consent at the beginning of the online and paper questionnaires and were informed that all data collected would be anonymous.

\section{Results}

This section provides a parsimonious description of the multiple statistics and tables generated by the PLS-SEM algorithm. Table 1 provides a summary of the measurement and structural model psychometric statistics of the adapted Thai version of the RSPWB. The six LVs: autonomy, environmental mastery, personal growth, purpose in life, positive relations with others, and self-acceptance) are listed across the top of Table 1 followed by the corresponding output for the validation of the measurement (convergent validity, discriminant validity, and composite reliability), and the structural models. As mentioned earlier, Lowry and Gaskin (2014) provide a detailed examination of how to apply PLS-SEM procedures to validate measurement and structural models and Calderon Jr. et al. (2019) demonstrates how a 54-item Vietnamese version of the RSPWB was adapted using PLS-SEM procedures. For a detailed description of the SmartPLS software (Ringle et al., 2005), procedures, and corresponding tables please refer to the above references.

Here, we provide a condensed explanation of the results. The first step in PLS-SEM analysis is to validate the measurement model before validating the structural model. In Table 1, under convergent validity, section 1.1.1 identifies, for each LV, the scale-items (indicators) that achieved T-statistics greater than 1.96. Indicators that achieve a T-statistics $>1.96$ indicate adequate convergent validity. Results from the convergent validity analysis showed that the loading coefficients (from the factor analysis scheme) of 7 different indicators ( 3 indicators from autonomy, 2 indicators from self-acceptance, and 1 indicator from personal growth, and purpose in life) did not reach statistical significance ( $t$-statistic of $>1.96)$. Thus, these 7 -indicators were dropped from the model. The remaining 47 -indicators of the original 54 indicators, among the six LVs, had loading coefficients with significant $t$-statistic values. This suggests that the 47-indicators shown in section 1.1.1 were valid and converged onto their respective LV. In turn, the 47-indicator model was used for subsequent analysis.

Next, the discriminant validity (section 1.2 of Table 1 ) of the 47 -indicator 
model was evaluated using two separate statistical outputs from the PLS-SEM algorithm, 1) the cross-loading coefficients, and 2) the average variance extracted (AVE) tables, respectively. Section 1.2.1 identifies the indicators in the final model with loading coefficients $>0.45$. Section 1.2.2 identifies the average loading coefficient per dimension. Section 1.2.3 identifies the square root of the average variance extracted (AVE).

To establish discriminant validity, the cross-loading coefficients on the primary LV should be more than the absolute value of 0.100 distant from the cross-loading coefficients of other LVs (Gefen \& Straub, 2005). Through an iterative process, indicators from the model that had loading coefficients of $<0.4$, or $>1.0$, or cross-loadings, of other LVs, less than the absolute value of 0.100 distant from the loading coefficient on the primary LV were dropped from the model one at a time. This process was continued until the loading coefficients of the remaining LVs reached the recommended value of 0.7 or higher or had an average loading per LV greater than 0.7 (Hair Jr. et al., 2016).

The above process (sections 1.2.1 and 1.2.2) resulted in a final model consisting of 23 indicators (i.e., Autonomy with 4, Environmental Mastery with 5, Personal Growth with 5, Purpose in Live with 3, Positive Relations with 2, and Self-Acceptance with 4), which suggests these 23 indicators had adequate convergent and discriminant validity.

Additional support for discriminant validity (section 1.2.3) was demonstrated by comparing the square root of the AVE to the correlation coefficients of the other LVs (Fornell \& Larcker, 1981). If the square root of the LV values on the diagonal line (table not shown) is greater than the correlation coefficients of the other variables this provides support for discriminant validity. The PLS algorithm AVE table showed that the square root for each LV was higher than the correlation coefficients of the other LVs. Thus, the overall discriminant validity of the final 23-item model was supported by two separate statistical outputs of the PLS-SEM algorithm.

For composite reliability (section 1.3 of Table 1), the PLS algorithm calculated a reliability coefficient for each LV. The composite coefficients of all LVs well exceed the recommended value of 0.700 suggesting that the final 23-indicator model reliably measured each construct in the model. The LVs with the highest and lowest composite coefficients were Personal Growth and Self-acceptance (0.906 and 0.809, respectively).

After the measurement model was validated then the structural model was assessed (see Figure 1, Table 1). Section 2.1 shows the path coefficients (regression weights of the path analysis) between each LV and the second-order variable of PWB and Section 2.2 shows their corresponding T-statistics. Strong and significant path coefficients from each LV to the second-order construct of PWB will support the proposed structural model. All six LVs (sub-constructs of PWB) had T-statistics far above the $1.96 \mathrm{~T}$-statistic needed to attain significance. This result provided support for the hypothesis that PWB is a multi-dimensional construct comprised of six sub-constructs (dimensions). The path from Personal 
Growth to PWB had the largest coefficient (0.3074), and Positive Relations with Others had the lowest coefficient (0.1420).

The descriptive statistics (means and standard deviations) for the six LVs in the model are as follows: Autonomy (Mean $=3.35 / \mathrm{SD}=0.77$ ), Environmental Mastery $($ Mean $=3.98 / \mathrm{SD}=0.74)$, Personal Growth $($ Mean $=3.88 / \mathrm{SD}=0.82)$, Purpose in Life (Mean $=4.43 / \mathrm{SD}=0.87$ ), Positive Relations with Others (Mean $=4.85 / \mathrm{SD}=0.85)$, and Self-Acceptance $($ Mean $=3.83 / \mathrm{SD}=0.72)$.

\section{Discussion}

As previously noted, few Thai instruments exist to measure PWB. One of the leading instruments, based on psychological theory, for assessing PWB is the RSPWB (Ryff, 1989, 2013). This study explained the steps taken to translate, pilot, validate, and adapt the 54-item RSPWB into a 23-item Thai version.

This study used PLS-SEM, a second-generation statistical technique because PLS-SEM is recommended for estimating (complex) path models with LVs and their relationships (Sarstedt et al., 2017) and it provided the statistical framework (Hair et al., 2017) to evaluate the validity and reliability of the resulting 23-item Thai version of the RSPWB.

Moreover, until recently, researchers have considered the PLS-SEM technique to be intimidating, and the software available to run PLS-SEM was not as developed as other SEM techniques and software, e.g. Covariance-based SEM (CB-SEM) and AMOS, respectively. Fortunately, new developments in PLS-SEM theory and statistical software (e.g., SmartPLS) have led more researchers to consider using PLS-SEM. For example, Lowry and Gaskin (2014) provided a systematic approach in how to apply, interpret, and assess the psychometrics of a PLS-SEM model. Also, they pointed out that in cases where a model contains formative constructs/indicators and more than 40 - 50 formative/reflective indicators, the PLS-SEM technique is a better choice compared to CB-SEM. Additionally, their example of how to use the SmartPLS2 software demonstrated PLS-SEM to be efficient and user-friendly. Thus, using PLS-SEM and SmartPLS should be a less intimidating and viable alternative tool for researchers interested in using structural equation modeling.

The results shown in Table 1 gave a summary of the key psychometric statistics of the adapted Thai version of the RSPWB. The overall outcome of the PLS-SEM analysis produced a 23-item Thai version of the RSPWB with acceptable convergent and discriminant validity and reliability. Moreover, the PLS-SEM analysis tested the path coefficients of the six sub-constructs (autonomy, environmental mastery, purpose in life, personal growth, positive relations with others, and self-acceptance), and their significance to the second-order LV of PWB (Figure 1). The results showed that the path coefficients of the six sub-constructs were all highly significant. This supported the assertion that the six sub-constructs can predict changes in the higher-order construct of PWB. It also suggests that the factorial structure of the 23-item Thai version of the RSPWB is consistent 
with the factorial structure (autonomy, environmental mastery, purpose in life, personal growth, positive relations with others, and self-acceptance) of the original RSPWB (Ryff, 1989). PWB may contain more than six factors, such as spirituality (van Dierendonck, 2004). However, more research needs to be conducted before the RSPWB is expanded to include additional dimensions/ factors.

Lastly, results from this study expand the findings reported by Klainin-Yobas et al. (2020), the first study to validate a version of the RSPWB in Thai. This study identified a 23-item Thai version of the RSPWB with good validity and reliability and a six-factor structure, whereas Klainin-Yobas et al. (2020) validated an 18-item Thai version of the RSPWB but only found a two-factor structure. This may have resulted for two reasons 1) the 54-item (nine-items per sub-construct) version of the RSPWB, used in this study, has stronger psychometric properties than the 18-item (three-items per sub construct) version of the RSPWB (Ryff, 1989) and 2) the nine-items per sub-construct provide a greater number of items to capture the essence and meaning of each sub-construct vs. only using three-items per sub-construct. This may be especially important when considering subtle nuances found in translating items from one language to another. In other words, using more items per construct, in the evaluation process, increases the odds of identifying the best items that reflect the meaning of that construct. In the end, the 18 and 23-item Thai versions of the RSPWB may be similar in length, however, the 23 -item Thai version supported a six-factor structure whereas the 18 -item Thai version did not.

\section{Strengths and Limitations}

This study was strengthened by a large sample size of university students $(\mathrm{N}=$ 1122) from two regions (north and central) in Thailand. Also, it used randomized cluster sampling, which included students from 31 different majors, 17 26 years of age, students in $1^{\text {st }}, 2^{\text {nd }}, 3^{\text {rd }}$, and $4^{\text {th }}$-year university levels, and two data collection tools (online and hard copy questionnaires). This was useful for internal validity and to increase the generalizability of research findings to students from other large universities in Thailand.

Furthermore, the use of PLS-SEM, a second-generation statistical technique, (with SmartPLS) provided a sophisticated way to examine the convergent and discriminant validity, the reliability, and factorial structure of the Thai version of the RSPWB. This adapted 23-item Thai version is a short and simple instrument that requires less time to complete, is easy to administer, and has good psychometric properties. Thus, there are now available two Thai versions of the RSPWB (18 and 23-item versions) which may be suitable for further research in community studies.

Nevertheless, this study has some limitations in that participants were exclusively university students. Therefore, our findings may not generalize to nonstudents in other settings or to the general population. 


\section{Conclusion}

The 23-item Thai version of the RSPWB demonstrated robust psychometric properties (convergent and discriminant validity, reliability, and consistent factorial structure with the original RSPWB). Also, PLS-SEM analysis provided an alternative approach for validating a popular version of the RSPWB. The practical implications from these results suggest that the 23 -item Thai version is shorter in length, takes less time to administer than the 54-item version, and can be used to measure the multiple dimensions of PWB among students (university and perhaps secondary school levels).

From a broader perspective, such as future research, it also implies that the 23-item Thai version can be used to develop PWB interventions, which can be offered to students according to their levels of PWB (such as developing, maintaining, and/or improving their well-being). Moreover, this scale can be used to facilitate future quantitative research such as investigating the effectiveness of interventions on $\mathrm{PWB}$, probing the predictive effect of PWB on academic and health-related outcomes.

Lastly, this study provides a model for other Southeast Asian countries to translate, pilot, and adapt the 54-item RSPWB into their local languages, which might help to facilitate further research in psychological well-being and its association with chronic diseases and health promotion.

\section{Acknowledgements and Funding}

No funding to declare.

A big thanks to all the students who took the time to fill out our questionnaire.

\section{Conflicts of Interest}

The authors declare no conflicts of interest regarding the publication of this paper.

\section{References}

Allport, G. W. (1961). Pattern and Growth in Personality. New York: Holt, Rinehart, and Winston.

Bühler, C. (1935). The Curve of Life as Studied in Biographies. Journal of Applied Psychology, 19, 405. https://doi.org/10.1037/h0054778

Calderon Jr., R., Nga, N. T., Tien, T. Q., Quyen, B. T. T., Thuan, N. H. M., \& Bao, V. V. (2019). Adapting the Ryff Scales of Psychological Well-Being: A 28-Item Vietnamese Version for University Students. VNU Journal of Social Sciences and Humanities, 5, 176-197. https://doi.org/10.33100/jossh5.2.Calderon.etal

Cheng, S.-T., \& Chan, A. C. M. (2005). Measuring Psychological Well-Being in the Chinese. Personality and Individual Differences, 38, 1307-1316. https://doi.org/10.1016/j.paid.2004.08.013

Chin, W. W. (1998). The Partial Least Squares Approach to Structural Equation Modeling. Modern Methods for Business Research, 295, 295-336. 
Dang, H. N. (2017). The Adaptation of the Ryff Scales of Psychological Well-Being among University Students. Journal of Psychology, 2, 77-89.

Dans, A., Ng, N., Varghese, C., Tai, E. S., Firestone, R., \& Bonita, R. (2011). The Rise of Chronic Non-Communicable Diseases in Southeast Asia: Time for Action. The Lancet, 377, 680-689. https://doi.org/10.1016/S0140-6736(10)61506-1

Deci, E. L., \& Ryan, R. M. (1990). A Motivational Approach to Self: Integration in Personality. In R. Dienstbier (Ed.), Nebraska Symposium on Motivation: Vol. 38. Perspectives on Motivation (pp. 237-288). Lincoln, NE: University of Nebraska Press.

Deci, E. L., \& Ryan, R. M. (2006). Hedonia, Eudaimonia, and Well-Being: An Introduction. Journal of Happiness Studies, 9, 1-11. https://doi.org/10.1007/s10902-006-9018-1

Dhillon, P. K., Jeemon, P., Arora, N. K., Mathur, P., Maskey, M., Sukirna, R. D., \& Prabhakaran, D. (2012). Status of Epidemiology in the WHO South-East Asia Region: Burden of Disease, Determinants of Health and Epidemiological Research, Workforce, and Training Capacity. International Journal of Epidemiology, 41, 847-860. https://doi.org/10.1093/ije/dys046

Diener, E. (1984). Subjective Well-Being. Psychological Bulletin, 95, 542-575. https://doi.org/10.1037/0033-2909.95.3.542

Erikson, E. H. (1994). Identity and the Life Cycle. New York: W. W. Norton \& Company.

Fornell, C., \& Larcker, D. F. (1981). Evaluating Structural Equation Models with Unobservable Variables and Measurement Error. Journal of Marketing Research, 18, 39-50. https://doi.org/10.1177/002224378101800104

Freire, C., Ferradás, M. D. M., Valle, A., Núñez, J. C., \& Vallejo, G. (2016). Profiles of Psychological Well-Being and Coping Strategies among University Students. Frontiers in Psychology, 7, 1554. https://doi.org/10.3389/fpsyg.2016.01554

Gao, J., \& McLellan, R. (2018). Using Ryff's Scales of Psychological Well-Being in Adolescents in Mainland China. BMC Psychology, 6, Article No. 17. https://doi.org/10.1186/s40359-018-0231-6

Gaskin, J. (2012). SmartPLS Factor Analysis. Gaskination's Statistics. http://youtube.com/Gaskination

Gefen, D., \& Straub, D. (2005). A Practical Guide to Factorial Validity Using PLS-Graph: Tutorial and Annotated Example. Communications of the Association for Information Systems, 16, 5. https://doi.org/10.17705/1CAIS.01605

Hair, J. F., Hult, G. T. M., Ringle, C. M., Sarstedt, M., \& Thiele, K. O. (2017). Mirror, Mirror on the Wall: A Comparative Evaluation of Composite-Based Structural Equation Modeling Methods. Journal of the Academy of Marketing Science, 45, 616-632. https://doi.org/10.1007/s11747-017-0517-x

Hair, J. F., Sarstedt, M., Pieper, T. M., \& Ringle, C. M. (2012). The Use of Partial Least Squares Structural Equation Modeling in Strategic Management Research: A Review of Past Practices and Recommendations for Future Applications. Long Range Planning, 45, 320-340. https://doi.org/10.1016/j.lrp.2012.09.008

Hair Jr., J. F., Hult, G. T. M., Ringle, C., \& Sarstedt, M. (2016). A Primer on Partial Least Squares Structural Equation Modeling (PLS-SEM). Thousand Oaks, CA: Sage Publications. https://doi.org/10.15358/9783800653614

Hernandez, R., Bassett, S. M., Boughton, S. W., Schuette, S. A., Shiu, E. W., \& Moskowitz, J. T. (2018). Psychological Well-Being and Physical Health: Associations, Mechanisms, and Future Directions. Emotion Review, 10, 18-29. https://doi.org/10.1177/1754073917697824

Jahoda, M. (1979). Current Concepts of Positive Mental Health. Manhattan, NY: Arno 
Press.

Jung, C. G. (1935). Modern Man in Search of a Soul. The Journal of Nervous and Mental Disease, 81, 715. https://doi.org/10.1097/00005053-193506000-00052

Kim, K.-M., \& Lim, J.-H. (2012). Effects of Optimism and Orientations to Happiness on Psychological Well-Being of College Students. Journal of the Korean Home Economics Association, 50, 89-101. https://doi.org/10.6115/khea.2012.50.1.089

Kitamura, T., Kishida, Y., Gatayama, R., Matsuoka, T., Miura, S., \& Yamabe, K. (2004). Ryff s Psychological Well-Being Inventory: Factorial Structure and Life History Correlates among Japanese University Students. Psychological Reports, 94, 83-103. https://doi.org/10.2466/pr0.94.1.83-103

Klainin-Yobas, P., Thanoi, W., Vongsirimas, N., \& Lau, Y. (2020). Evaluating the English and Thai-Versions of the Psychological Well-Being Scale across Four Samples. Psychology, 11, 71-86. https://doi.org/10.4236/psych.2020.111006

Lapa, T. Y. (2015). Physical Activity Levels and Psychological Well-Being: A Case Study of University Students. Procedia-Social and Behavioral Sciences, 186, 739-743. https://doi.org/10.1016/j.sbspro.2015.04.122

Lowry, P. B., \& Gaskin, J. (2014). Partial Least Squares (PLS) Structural Equation Modeling (SEM) for Building and Testing Behavioral Causal Theory: When to Choose It and How to Use It. IEEE Transactions on Professional Communication, 57, 123-146. https://doi.org/10.1109/TPC.2014.2312452

Lyubomirsky, S., \& Tucker, K. L. (1998). Implications of Individual Differences in Subjective Happiness for Perceiving, Interpreting, and Thinking about Life Events. Motivation and Emotion, 22, 155-186. https://doi.org/10.1023/A:1021396422190

Maslow, A. H. (1962). Toward a Psychology of Being. New York: Van Nostrand. https://doi.org/10.1037/10793-000

Neugarten, B. L. (1968). Middle Age and Aging: A Reader in Social Psychology. Chicago, IL: University of Chicago Press.

Ringle, C. M., Wende, S., \& Will, A. (2005). SmartPLS 2.0.M3 (2.0) [Computer Software]. SmartPLS. http://www.smartpls.com

Rogers, R. C. (1961). On Becoming a Person: A Therapist's View of Psychotherapy. London: Constable.

Ryan, R. M., \& Deci, E. L. (2001). On Happiness and Human Potentials: A Review of Research on Hedonic and Eudaimonic Well-Being. Annual Review of Psychology, 52, 141-166. https://doi.org/10.1146/annurev.psych.52.1.141

Ryff, C. D. (1989). Happiness Is Everything, or Is It? Explorations on the Meaning of Psychological Well-Being. Journal of Personality and Social Psychology, 57, 1069-1081. https://doi.org/10.1037/0022-3514.57.6.1069

Ryff, C. D. (2013). Psychological Well-Being Revisited: Advances in the Science and Practice of Eudaimonia. Psychotherapy \& Psychosomatics, 83, 10-28. https://doi.org/10.1159/000353263

Ryff, C. D., Singer, B. H., \& Dienberg Love, G. (2004). Positive Health: Connecting Well-Being with Biology. Philosophical Transactions of the Royal Society of London. Series B: Biological Sciences, 359, 1383-1394. https://doi.org/10.1098/rstb.2004.1521

Sarstedt, M., Ringle, C., \& Hair, F. J. (2017). Partial Least Squares Structural Equation Modeling. In Handbook of Market Research (pp 1-40). Berlin: Springer. https://doi.org/10.1007/978-3-319-05542-8_15-1

Seligman, M. E. P. (2012). Flourish: A Visionary New Understanding of Happiness and Well-Being. New York: Simon and Schuster. 
van Dierendonck, D. (2004). The Construct Validity of Ryff's Scales of Psychological Well-Being and Its Extension with Spiritual Well-Being. Personality and Individual Differences, 36, 629-643. https://doi.org/10.1016/S0191-8869(03)00122-3

Woo Kyeong, L. (2013). Self-Compassion as a Moderator of the Relationship between Academic Burnout and Psychological Health in Korean Cyber University Students. Personality and Individual Differences, 54, 899-902.

https://doi.org/10.1016/j.paid.2013.01.001 